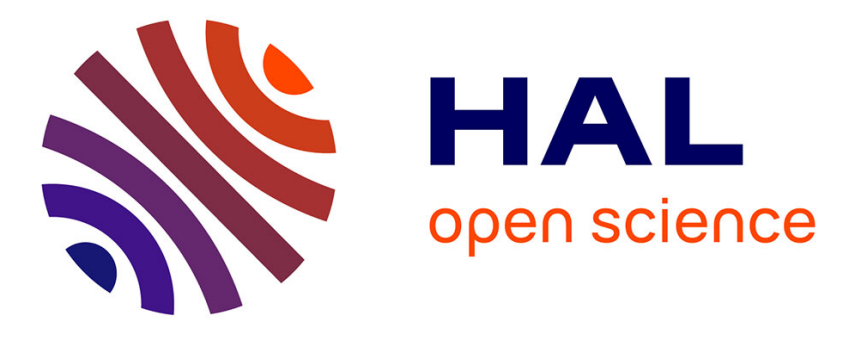

\title{
Effect of ageing on mobility and sequestration of phenanthrene in an agricultural soil
}

Samira Amellal, Arnaud Boivin, Corinne Perrin Ganier, Michel Schiavon

\section{To cite this version:}

Samira Amellal, Arnaud Boivin, Corinne Perrin Ganier, Michel Schiavon. Effect of ageing on mobility and sequestration of phenanthrene in an agricultural soil. Agronomy for Sustainable Development, 2006, 26 (4), pp.269-275. 10.1051/agro:2006026 . hal-02654261

\section{HAL Id: hal-02654261 https://hal.inrae.fr/hal-02654261}

Submitted on 29 May 2020

HAL is a multi-disciplinary open access archive for the deposit and dissemination of scientific research documents, whether they are published or not. The documents may come from teaching and research institutions in France or abroad, or from public or private research centers.
L'archive ouverte pluridisciplinaire HAL, est destinée au dépôt et à la diffusion de documents scientifiques de niveau recherche, publiés ou non, émanant des établissements d'enseignement et de recherche français ou étrangers, des laboratoires publics ou privés.

$$
\text { Copyright }
$$




\title{
Effect of ageing on mobility and sequestration of phenanthrene in an agricultural soil
}

\author{
Samira Amellat*, Arnaud Boivin, Corinne PerRin Ganier, Michel Schiavon \\ Laboratoire Sols et Environnement, ENSAIA-INRA/INPL, 2 avenue de la Forêt de Haye, BP 172, 54505 Vandœuvre-lès-Nancy Cedex, France
}

(Accepted 27 September 2006)

\begin{abstract}
We studied the effect of ageing on the mobility and sequestration of ${ }^{14} \mathrm{C}$-phenanthrene in an agricultural soil. We used autovial microcolumns incubated for a period ranging between 0 and 156 days. Our results showed that a large proportion of radioactivity remained extractable by methanol up to 64 days of incubation, amounting from 44.5 to $80.2 \%$ of initial radioactivity. Mineralisation of ${ }^{14} \mathrm{C}$-phenanthrene began tardily, after the decrease of mineralisation of the soil organic matter. Throughout incubation, mineralisation remained slow and weak, of co-metabolic type, and only $2 \%$ of the quantity applied was mineralised over a period of 156 days. The amount of radioactivity leached varied considerably during incubation. Under the effect of water percolation of $64 \mathrm{~mm}$, the quantities exported in equivalent ${ }^{14} \mathrm{C}$-phenanthrene went from 0.90 to $0.48 \mathrm{ng} / \mathrm{g}$ of soil between 0 and 35 days, then increased up to $1.5 \mathrm{ng} / \mathrm{g}$ at 100 days. The radioactivity present in pore water displayed the same dynamic and the same variations. For pore water, this radioactivity represented, in equivalent phenanthrene, $0.09 \mathrm{ng} / \mathrm{g}$ of soil up to 46 days, then increased rapidly to reach $0.5 \mathrm{ng} / \mathrm{g}$ at 65 days. In both cases (leachates and pore water), enrichment in radioactivity due to the presence of a high proportion of polar compounds reached $89 \%$. Lastly, the formation of non-extractable residues progressed very slowly up to 45 days (5.9 to $13 \%$ of the amount applied), after which there was a marked increase, i.e. to $20.7,32.2$ and $35.8 \%$ at 52,64 and 156 days, respectively. These increases in radioactivity in different compartments of soil are correlated with mineralisation of phenanthrene due to preliminary production of degradation products. Thus, the capacity of a soil to degrade and mineralise phenanthrene plays a determining role in the distribution of its residues between the soil solution and the solid matrix. Overall, our results suggest that in agricultural soils contaminated by strongly adsorbed organic compounds, water pollution and sequestration are primarily controlled by degradation.
\end{abstract}

PAH / leaching / diffusion / sequestration / mineralisation / agricultural soil / water quality

\section{INTRODUCTION}

Polycyclic aromatic hydrocarbons (PAHs) of anthropic origin that settle and accumulate on the surface of the soil are a significant class of organic contaminants because of their toxicity and persistence (Cerniglia, 1993). A significant environmental concern with PAHs is their ability to accumulate as non-extractable residues or to move through the soil and contaminate surface water or deeper groundwater (Ho and Hui, 2001; Lichtfouse et al., 2005).

There are considerable variations in the behaviour of an organic compound in the soil. These variations are mainly due to the compound's chemical structure, which governs its adsorption by the soil and controls its availability for biological degradation, movement and sequestration. Interactions between these different processes, plus the influence of environmental factors, generally results in a decrease in the availability of the product with an increase in residence time in the soil (Walker et al., 2005). One of these processes, adsorption, plays a particular role insofar as it contributes to limiting the concentration of the product in the soil solution and thus its availability for biological degradation or leaching (Yaduraju, 1994; Anderson, 1994). This interaction between an organic

\footnotetext{
*Corresponding author: Samira.Amellal@ensaia.inpl-nancy.fr
}

compound and the soil varies with time and its distribution between the dissolved and adsorbed state can require several days, weeks or even months to reach equilibrium (Cox and Walker, 1999; Koskinen et al., 2002). Conversely, desorption favours the return of the product into the soil solution. However, desorption is always slow, requires energy and is generally not entirely reversible (Boivin et al., 2005). In addition, the role played by diffusion is ambiguous. The diffusion of the product from the surface of the aggregates towards the spaces occupied by immobile water (pore water) can limit its availability for degradation or leaching (a well), but it can also constitute a source of the product when there is a connection between pore water and mobile water. In immobile water and its associated microporosity, the product may constitute a well or source for the mobile water (Lennartz and Meyer-Windel, 1995). Degradation, which is supposed to occur on the surface of the aggregates and is linked with the pollutant available in the soil solution (Dictor et al., 2003; Scow and Johnson, 1997), can also intervene in a complex way. Depending on its nature and on environmental conditions, soil microflora plays a more or less active role in the transformation of the initial bioavailable product. This transformation then results in compounds which are generally more soluble and/or more reagents and can continue until mineralisation occurs. Thus, over time 
Table I. Selected characteristics of the 2-5 mm fraction of the sandy loam soil. CEC: cation exchange capacity; OC: organic carbon; ON: organic nitrogen; RC: retention capacity.

\begin{tabular}{lcccccccc}
\hline Soil & Clay & Silt & Sand & $\mathrm{pH}_{\mathrm{H}_{2} \mathrm{O}}$ & $\begin{array}{c}\mathrm{CEC} \\
(\mathrm{cmol} / \mathrm{kg})\end{array}$ & $\begin{array}{c}\mathrm{OC} \\
(\%)\end{array}$ & $\begin{array}{c}\mathrm{ON} \\
(\%)\end{array}$ & $\begin{array}{c}\mathrm{RC} \\
(\%) \mathrm{pF} 2.1\end{array}$ \\
\hline Sandy loam & 12.7 & 13.8 & 73.5 & 6.4 & 4.6 & 0.83 & 0.082 & 19 \\
\hline
\end{tabular}

microflora helps reduce the fraction available for diffusion, sequestration and leaching (Renaud et al., 2004; Walker et al., 2005). Conversely, the resulting products can be diffused and thus not available for mineralisation or leaching, in particular when degradation is slow (fortuitous degradation or cometabolic degradation) (Soulas, 1993). Lastly, the sequestration or formation of non-extractable residues can contribute in a very significant and quasi-final way to the exclusion of the pollutant from any other process which defines its behaviour in the soil (Scheunert et al., 1991). In this context, the aims of our work were to study the effects of ageing phenanthrene in an agricultural soil. To this end, we simultaneously observed the product's degradation, diffusion in the immobile water inside the aggregates, sequestration, and finally, the consequences of these processes on its availability for leaching.

\section{MATERIALS AND METHODS}

\subsection{Chemical}

[Benzene ring-U ${ }^{14} \mathrm{C}, 9-{ }^{14} \mathrm{C}$ ]-phenanthrene was obtained from American Radio Labeled Chemicals and diluted in ethanol. Its specific radioactivity was $2.035 \mathrm{GBq} / \mathrm{mmol}$ and its radiochemical purity $99.8 \%$.

\subsection{Soil}

Five days before the beginning of the experiments, the sandy loam soil used in our studies was removed from the surface layer $(5-15 \mathrm{~cm})$ of an agricultural soil in eastern France (Villey-St-Étienne, France). Selected physico-chemical characteristics of the soil are given in Table I. After drying at ambient laboratory temperature $\left(20 \pm 2{ }^{\circ} \mathrm{C}\right)$, the soil was carefully sieved to between 2 and $5 \mathrm{~mm}$ so that its structure was similar to an aggregated seedbed. Table I also includes estimates of the soil water retention capacity (RC), which is defined here as the amount of pore water retained by the soil at $p F=2.1$ (Duchaufour, 1970).

\subsection{Soil spiking with ${ }^{14} \mathrm{C}$-phenanthrene}

After homogenisation, the sieved soil at $7.2 \%$ humidity was divided into equivalent 10-g dry fractions and spread as a 5$\mathrm{mm}$ layer in a Petri dish (diameter $10 \mathrm{~cm}$ ). Each fraction received $1.62 \mu \mathrm{g}$ of ${ }^{14} \mathrm{C}$-phenanthrene, corresponding to 188.9 $\mathrm{KBq}$ in a $0.5 \mathrm{~mL}$ methanol solution. The solution was sprayed onto the aggregate surfaces by means of a microsyringe that dispensed very small droplets $(2-3 \mu \mathrm{L})$ without imbibition of the aggregates. After complete evaporation of the solvent, the soil samples were homogenised. Three replicates were made of each treatment. Control treatments without phenanthrene consisted of the same weight of soil and the same volume of water without methanol.

\subsection{Experimental device}

Whatman autovial microcolumns with a centric outlet (Whatman PLC, Newton, MA) were used for our experiments. These microcolumns (internal diameter of $2 \mathrm{~cm}$ and $5.4 \mathrm{~cm}$ high) were previously used to assess pesticide dynamics in different agricultural soil samples (Beulke et al., 2004; Guimont et al., 2005). The autovials had a glass microfibre filter $(0.45 \mu \mathrm{m})$ at the bottom perforated with eight $1-\mathrm{mm}$ holes. The inside surface of the autovials was covered with aluminium foil to avoid contact between the soil and the polypropylene walls and they were then filled with $10.72 \mathrm{~g}$ of contaminated soil aggregates. In their dry state, the soil columns were $3 \mathrm{~cm}$ high, and their density was $1.06 \pm 0.02$. With $10 \mathrm{~mm}$ water pressure, the infiltration rate was, at equilibrium, $24.4 \pm 0.9 \mathrm{~mm} / \mathrm{min}$ (Guennelon, 1994). After moistening to $100 \%$ of their soil water retention capacity, the soil columns were incubated in 0.5 -litre radio-respirometers that contained one flask of aqueous sodium hydroxide (0.5 M; $10 \mathrm{~mL}$ ) and one flask filled with distilled water. The sodium hydroxide was used to trap carbon dioxide evolving from the soil as well as $\left[{ }^{14} \mathrm{C}\right]$ carbon dioxide resulting from the degradation of the phenanthrene ${ }^{14} \mathrm{C}$-ring. The flask filled with distilled water was used to reduce water losses from the soil by maintaining the water content in the system. The radiorespirometers were incubated in the dark at $25 \pm 2{ }^{\circ} \mathrm{C}$.

Carbon dioxide released from the microcolumns was measured after $0,3,8,14,25,35,46,52,64,100$ and 156 days, and on the same dates 3 autovials were used for leaching and centrifugation experiments. After leaching and centrifugation, the radioactivity of the two fractions of obtained water was measured. Finally, the soil was removed and subjected to exhaustive extraction by methanol followed by combustion to quantify the non-extractable radioactivity fraction (sequestered residues). The different steps are described in more detail below.

\subsection{Leaching experiment with autovials}

To evaluate the quantities of easily available radioactivity $\left({ }^{14} \mathrm{C}\right.$-phenanthrene and ${ }^{14} \mathrm{C}$-degradation products $)$ present at the surface of the aggregates and their evolution over the period of incubation, the microcolumns were subjected to leaching. 


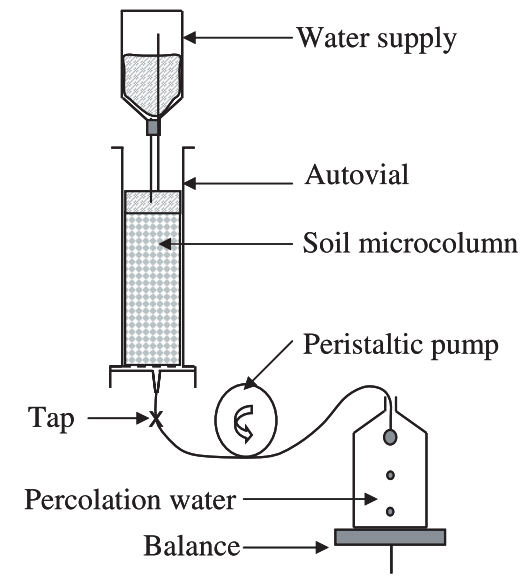

Figure 1. Experimental device used for the percolation of the microcolumns.

Radioactivity in the leachates was measured after $0,3,8$, $14,25,35,46,52,64,100$ and 156 days. For this purpose, the microcolumns, at $100 \%$ of their retention capacity, were connected to a mp25 peristaltic pump (Ismatec, Glattbrugg, Switzerland) which ensured a flow of $0.995 \pm 0.01 \mathrm{~mm} / \mathrm{min}$ (Fig. 1). The total volume of water applied to the top of the microcolumns $(20 \pm 0.01 \mathrm{~mL})$ was recovered as percolation water. At the end of the leaching process, the pump's tubing was rinsed with $10 \mathrm{~mL}$ of methanol solution in order to collect any radioactivity that may have adsorbed on the tubing walls.

Next, radioactivity in the leachates was measured using a Packard tri-carb 2100 TR liquid scintillation analyser (Packard Instrument Company, Medriden, CT) after adding $10 \mathrm{~mL}$ of a scintillation cocktail (Ultima Gold, Packard Bioscience). The counting time was $10 \mathrm{~min}$, and quench correction was made by the scintillator analyser after calibration.

\subsection{Centrifugation of autovials}

Centrifugation experiments were performed to measure the radioactivity present in the pore water fraction of the soil, i.e., water remaining in the micropores of the aggregates. The microcolumns were centrifuged using a Beckman Avanti ${ }^{\mathrm{TM}}$ J25 (Beckman Instrument, Fullerton, CA) with a centrifugal force of $7244 \mathrm{~g}$ (pF 3.9) for $10 \mathrm{~min}$ to evacuate water more strongly retained in the soil micropores $(57.2 \pm 1.3 \%$ of the soil retention capacity). The centrifugal force applied corresponded to the crush resistance limit of the glass flasks attached to the bottom of the microcolumns to collect the soil water (Fig. 2). This centrifugal step enabled water retained in the very fine micropores to be collected (Guimont et al., 2005). Once the pore water was collected and its volume measured, radioactivity was measured by scintillation (as described above).

\subsection{Nature of ${ }^{14} \mathrm{C}$-compounds in the leachates and in extracted pore water}

Each sample of water (leachates or pore water) was extracted with dichloromethane by liquid/liquid partitioning.

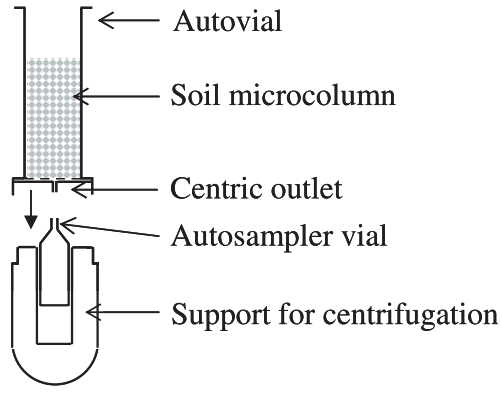

Figure 2. Experimental autovial microcolumn filled with soil aggregates and one autosampler vial on a support designed for centrifugation. Both can be connected using the centric outlet located at the bottom of the microcolumn.

Two successive extractions were performed, each lasting for $10 \mathrm{~min}$. This method gave an extraction rate of $96 \pm 3.5 \%$ of phenanthrene from pure water. At the end of the procedure, some of the ${ }^{14} \mathrm{C}$-compounds remained in the water; these are referred to hereafter as "polar compounds". Those dissolved in solvent are referred to as "non-polar compounds". The relative distribution of polar and non-polar compounds was calculated after analysis of the extracts by liquid scintillation as described above.

\subsection{Extractable radioactivity and analysis}

Following the centrifugation experiment and collection of water, the soil was removed from the microcolumns and dried at ambient laboratory temperature $\left(20 \pm 2{ }^{\circ} \mathrm{C}\right)$. The soil samples were subsequently extracted exhaustively using the soxhlet method. Methanol was used to extract any polar compounds resulting from biodegradation of phenanthrene (Amellal et al., 2006). Complementary experiments showed that the exhaustive extraction of phenanthrene by methanol or dichloromethane led to the same extraction rate. The series of extractions were carried out sequentially and terminated when the radioactivity measured in the methanol was close to the scintillator analyser background noise.

Upon completion of the methanol extractions, the supernatants were combined and concentrated for analysis of degradation products by high-performance liquid chromatography (HPLC) in a Varian chromatograph equipped with a diode array detector and a radioactivity $\beta$ detector (Flo-one $\beta$, Packard) with the following operating conditions: C18 column $4.6 \times$ $250 \mathrm{~mm}$ spheri ODS $5 \mu$ (Perkin Elmer), injection volume $100 \mu \mathrm{L}$, analysis time $28 \mathrm{~min}$, flow rate $0.8 \mathrm{~mL} / \mathrm{min}$, gradient elution acetonitrile/water: $0 \mathrm{~min}(50 / 50), 3 \mathrm{~min}(60 / 40)$, $15 \min (90 / 10), 21 \mathrm{~min}(95 / 5)$. Detection was performed in the following conditions: (1) $\beta$ radioactivity detector: Scintillator Ultima-Flo, flow $1.2 \mathrm{~mL} / \mathrm{min}$, counting cell $500 \mu \mathrm{L}$ and (2) diode array detector: wavelength $249 \mathrm{~nm}$, standards of the phenanthrene and 9,10-phenanthrenedione (mixed with acetonitrile) (Cluzeau France, Purity $>99 \%$ ) for calibration (10, $7.5,5,2.5$ and $1.225 \mu \mathrm{g} / \mathrm{L})$. The retention times were 7.5 and 


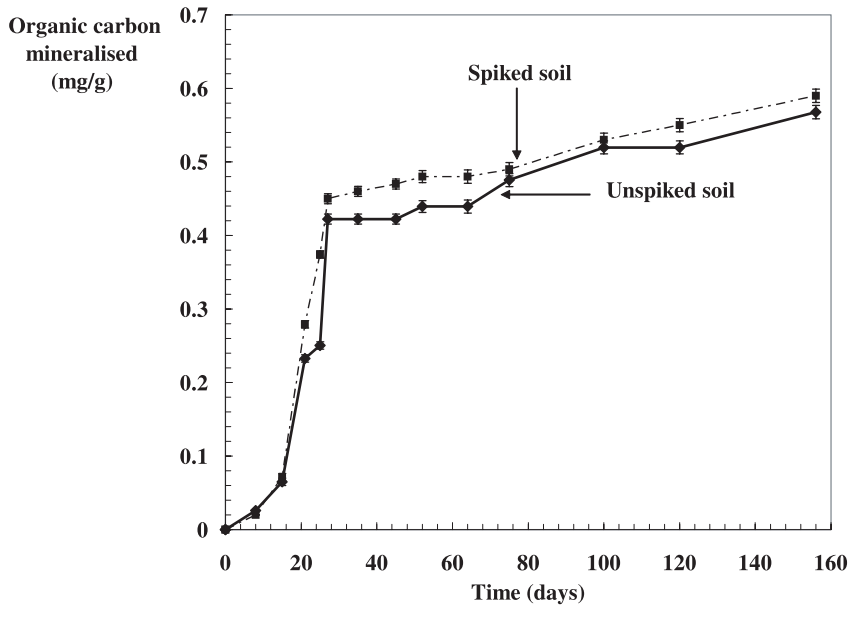

Figure 3. Changes in amounts of organic carbon mineralised $(\mathrm{mg} / \mathrm{g}$ of soil) in the sandy loam soil spiked or unspiked (without phenanthrene and methanol) over the 156-day incubation period. Standard deviations are indicated for each time interval.

17 min for 9,10-phenanthrenedione and phenanthrene, respectively.

\subsection{Non-extractable radioactivity}

After exhaustive extraction of the radioactivity by soxhlet, the soil aggregates were air-dried and pulverised. Nonextractable ${ }^{14} \mathrm{C}$-residues were then determined by combustion of the soil samples $(0.3 \mathrm{~g})$ mixed with cellulose powder $(0.15 \mathrm{~g})$. The samples were burned at $900{ }^{\circ} \mathrm{C}$ with an Oxidizer 307 (Packard Instrument Company, Meridien, CT). $\left[{ }^{14} \mathrm{C}\right]$ carbon dioxide released by the samples was trapped using $10 \mathrm{~mL}$ of Carbo-sorb E (Packard) and a 10-mL scintillating solution Permafluor $\mathrm{E}^{+}$(Packard) was subsequently added and the radioactivity of the trapped solution determined using liquid scintillation.

\section{RESULTS AND DISCUSSION}

\subsection{Mineralisation of soil organic carbon and ${ }^{14} \mathrm{C}$-phenanthrene}

Mineralisation of total carbon was monitored during incubation to check the activity of the microflora. Mineralisation of the soil organic carbon of the samples (spiked or unspiked) started almost immediately (Fig. 3). Our results also showed that mineralisation continued throughout the period of incubation. The total amount of organic carbon mineralised over the 156 -day incubation period was $0.6 \pm 0.01 \mathrm{mg}$ per $\mathrm{g}$ of soil, corresponding to $6.8 \%$ of the carbon initially present in the soil. These results revealed good activity of the microflora. A comparison between spiked and unspiked assays (controls without methanol and phenanthrene) incubated under the same conditions showed that addition of phenanthrene and methanol did not significantly affect the mineralisation rate (Fig. 3). These

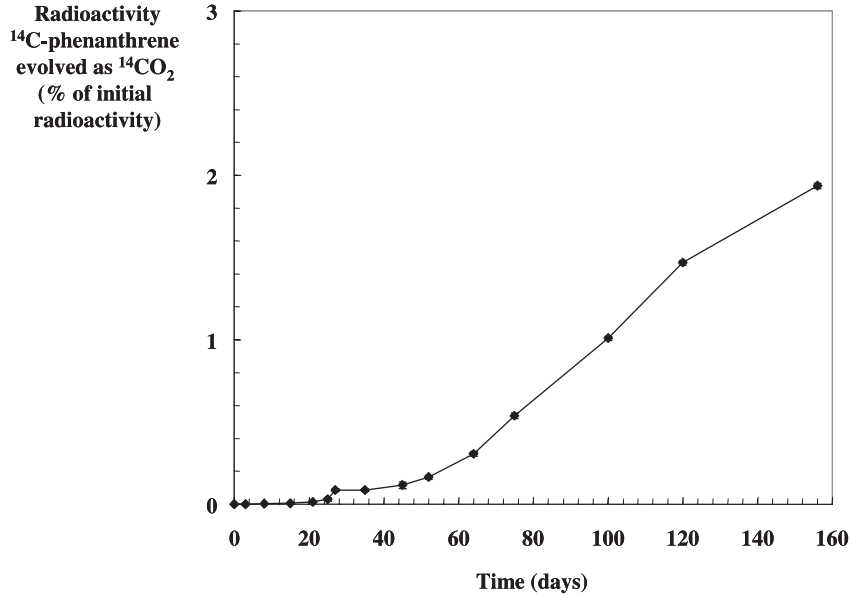

Figure 4. Mineralised amounts (in \% of the initial radioactivity applied) of ${ }^{14} \mathrm{C}$-phenanthrene in the soil over the 156-day incubation period. Mineralisation was efficient only after 52 days of incubation. Standard deviations calculated at each time interval are too low to be visible.

results showed that the degradation of phenanthrene was not affected by the initial methanol applied and that the solvent added during treatment was indeed eliminated by volatilisation.

Mineralisation of ${ }^{14} \mathrm{C}$-phenanthrene appears to be a slow process. Over the whole 156-day incubation period, the cumulative percentage of ${ }^{14} \mathrm{C}$-dioxide carbon released was only $1.9 \pm 0.05 \%$ of the dose initially applied. Figure 4 shows the absence of mineralisation during the first 20 days followed by slow progression up to 45 days, showing adaptation by the microflora. The degrading microflora seems to have reached its optimal development for this soil from 54 days. It is interesting to note that mineralisation of phenanthrene only began when mineralisation of organic carbon slowed down. The lack of substrate for the microflora would then make it possible for the degrading populations to develop, as competition with other microbial populations is reduced.

Mineralisation of phenanthrene in this soil may have been restricted because of a number of environmental factors, including slow development of non-adapted native microflora $(\mathrm{pH}=6.4)$, and/or the absence of the co-substrate required for initial oxidation of the phenanthrene molecule (Chang et al., 2002). Moreover, adsorption/sequestration of phenanthrene residues by the soil could also contribute to limiting degradation.

\subsection{Evolution of extractable radioactivity of the soil}

The extractable radioactivity corresponded to the fraction of residues $\left({ }^{14} \mathrm{C}\right.$-phenanthrene and ${ }^{14} \mathrm{C}$-degradation products) available after the series of extractions. Figure 5 shows data obtained from the extraction of the radioactivity by the soxhlet method. The rate of extractable radioactivty during the incubation period decreased from $80 \pm 3 \%$ of the initial radioactivity at T0 (initial application) to $25 \pm 1.4 \%$ after 156 days 


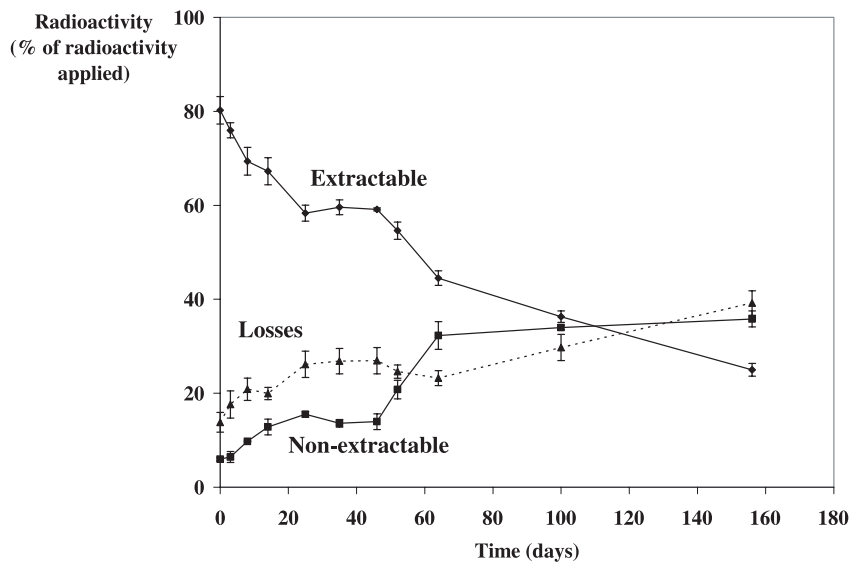

Figure 5. Changes in the amounts of extractable and non-extractable radioactivity and losses of radioactivity in the sandy loam soil (in $\%$ of the initial radioactivity applied) measured over the 156-day incubation period.

of incubation. According to Breedveld and Karlsen (2000), the extractable fraction is a good indicator of the potential biodegradable fraction, as the mineralisation process slows down as soon as the extractable fraction decreases. However, it should be noted that our results do not agree with this statement (Figs. 4, 5). The low ${ }^{14} \mathrm{C}$-phenanthrene mineralisation rate was not necessarily due to its low bioavailability since the extractable fraction remained high during the first 64 days of incubation. In our case, the limiting factor for mineralisation could be a lack of micro-organisms able to mineralise phenanthrene and/or a lack of co-substrate.

\subsection{Nature of the radioactivy extracted from the soil}

In soils, initial oxidation and ring cleavage of phenanthrene can result in the formation of small amounts of various degradation products which generally have higher polarity. Analysis of the extracted compounds by high-performance liquid chromatography (HPLC) revealed the presence of 3 degradation products, but only after 35 incubation days. However, this does not exclude the presence of other products at concentrations below the quantification limit $(5400 \mathrm{~Bq} / 100 \mu \mathrm{L})$. These 3 polar compounds accounted for 1.5, 4.1, 4.5 and $4.4 \%$ of the total amount of residue extracted from the soil after 46, 52, 64 and 156 incubation days, respectively. Only the prevalent product, 9,10-phenanthrenedione, was identified. The very low quantities of degradation products can be interpreted in different ways: (1) slight degradation of phenanthrene in soil, (2) the leaching of the majority of the metabolites before sampling of the soil columns for analysis, (3) the rapid sequestration of the degradation products (Weigand et al., 2002) and (4) progressive mineralisation by microflora after its formation.

\subsection{Leaching of radioactivity}

Figure 5 shows the quantities of radioactivity leached from the day of the initial application (T0) up to day 156. The quan-

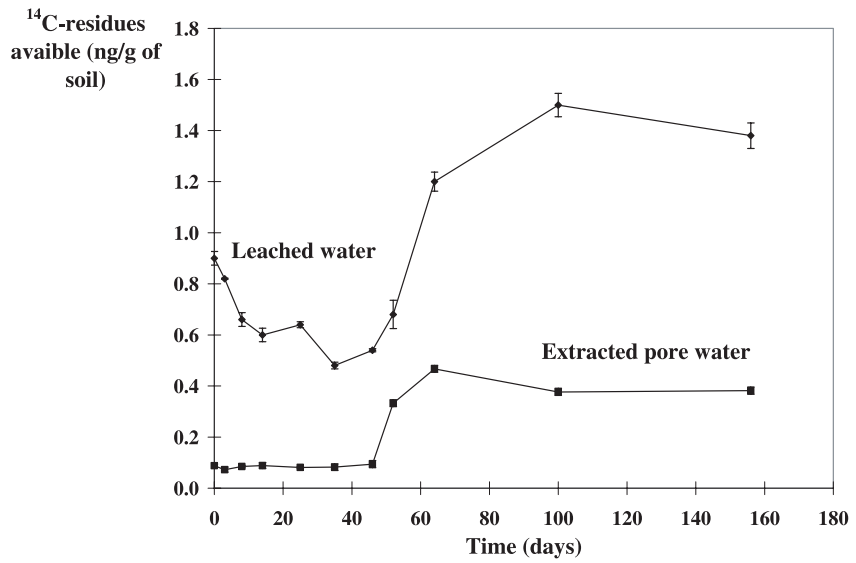

Figure 6. Amounts of residues expressed in ${ }^{14} \mathrm{C}$-phenanthrene equivalent (ng/g of soil) in two soil water fractions (leached and extracted pore water) over the 156-day incubation period. The washed or extracted quantities only started to increase when mineralisation of phenanthrene began. Standard deviations are also shown but nonvisible for extracted pore water.

tities of leached radioactivity were relatively low, ranging from $0.9 \pm 0.05$ to $1.38 \pm 0.04 \mathrm{ng} / \mathrm{g}$ of the soil (expressed in ${ }^{14} \mathrm{C}$ phenanthrene equivalent) over the whole incubation period. This corresponds to total lixiviated amounts of only $0.05 \%$ to $0.84 \%$ of the applied dose. However, between 0 and 35 days of incubation, the quantities of radioactivity leached decreased from $0.9 \pm 0.05$ to $0.48 \pm 0.03 \mathrm{ng} / \mathrm{g}$, then, at day 46 , they increased to reach a maximum of $1.50 \pm 0.02 \mathrm{ng} / \mathrm{g}$ after 100 days of incubation (Fig. 6).

Phenanthrene is not very soluble and has a high affinity for the solid phase. Nevertheless, the low radioactivity (or concentrations in residues) observed in the leaching water depends on the mode of circulation of water through the soil. In our working conditions, i.e. soil sieved at $2-5 \mathrm{~mm}$, initial moisture at $100 \%$ soil water retention capacity and an infiltration rate of $0.995 \mathrm{~mm} / \mathrm{min}$, water circulates primarily in the macropores (inter-aggregate spaces). Consequently, any exchanges mainly involve residues present at the surface of the aggregates. Desorption is only partial and occurs in conditions of non-equilibrium (short percolation time) which consequently limits the processes of solubilisation and/or desorption of the phenanthrene residues.

The decrease in the amounts of leached radioactivity during the first 35 days of incubation may be due to increased interactions between the soil components and the phenanthrene. In addition, some phenanthrene residues may have diffused into less accessible regions, e.g. immobile water within the micropores of aggregates. However, after 46 days of incubation we observed a significant increase in the leached residues. The control of organic carbon concentrations dissolved in the leachates, which was very weak and did not vary over time, excludes the possibility of a colloidal transport (result not shown). This increase coincided with the start of phenanthrene mineralisation (Fig. 4) and the production of metabolites which are more polar and/or more water-soluble. 
This resulted in an increase in leaching (Fig. 6). Unfortunately, the small amounts of ${ }^{14} \mathrm{C}$-residues recovered did not allow us to carry out a detailed HPLC analysis. However, we did succeed in separating them into polar and non-polar compounds through a series of extractions with dichloromethane. These results showed that, up to 35 days of incubation, only non-polar compounds were present in the leachates, probably phenanthrene. Thereafter, the proportion of non-polar compound decreased and represented 90,71, 47, 11 and $12 \%$ after $46,52,64,100$ and 156 days, respectively. It is thus the polar compounds that contaminate water.

\subsection{Radioactivity in extracted pore water}

During the first 46 days of incubation, the radioactivity in the pore water compartment measured by centrifugation remained low (equivalent to $0.09 \mathrm{ng}$ of ${ }^{14} \mathrm{C}$-phenanthrene/g of soil) and more or less constant (Fig. 6). These results indicate a weak presence of soluble molecules in pore water during the non-mineralisation phase. This could be due to the transport of ${ }^{14} \mathrm{C}$-phenanthrene by methanol towards microporosity during the treatment. But this explanation is not very probable because the product is rapidly and strongly adsorbed by this soil (distribution coefficient between soil and water $(\mathrm{Kd})=180$ ) and during the application, there is no imbibition of the aggregates. Moreover, the use of dichloromethane, which is less invasive, for the application of the product in preliminary tests did not significantly change the results. On the other hand, after 52 days of incubation, the radioactivity extracted by pore water increased considerably $(0.5 \pm 0.03 \mathrm{ng} / \mathrm{g}$ at 64 days $)$. This increase was slightly delayed with respect to that observed at the surface of the aggregates during leaching. It also began a short time before the intense mineralisation phase, i.e. during the degradation stage that preceded it. This increase in the concentrations of radioactivity extracted by pore water probably reflects the start of the process of diffusion. Diffusion would be facilitated by a gradient of concentration created by the strong concentration in the polar residues present in the film of water surrounding the aggregates and evaluated by leaching. In addition, the quantities of ${ }^{14} \mathrm{C}$-non-polar residues present in extracted pore water were appreciably constant $(0.08 \mathrm{ng} / \mathrm{g}$ of soil) and only the polar fraction increased. Indeed, separating the compounds in the pore water into polar and non-polar fractions by dichloromethane extraction showed that $98 \%$ of the non-polar compounds were still present after the first 46 days of incubation, but then decreased to $24.9,17.7,22.0$ and $21.7 \%$ after 52, 64, 100 and 156 days, respectively. This tends to indicate that certain degradation products, that are probably more soluble and less subject to sorption than phenanthrene, are potentially more subject to diffusion into intra-aggregate micropores.

\subsection{Non-extractable radioactivity and ${ }^{14} \mathrm{C}$ mass balance}

Non-extractable radioactivity is defined here as that which had not been extracted from the soil after the series of ex- tractions with methanol (exhaustive extraction). At T0, i.e. the moment of contamination, we observed the formation of $6 \pm 0.3 \%$ of non-extractable residues (Fig. 5). The amount of non-extractable residues increased only minimally between 0 and 45 days of incubation, possibly because phenanthrene was initially strongly adsorbed on aggregate surfaces with only limited partitioning in the soil solution, thus preventing its subsequent diffusion and sequestration in the aggregates. On the other hand, an increase in the non-extractable fraction of radioactivity was observed between 45 and 64 days of incubation at the same time as an increase in phenanthrene mineralisation (Fig. 4). Being mobile and/or more reactive than phenanthrene, a fraction of the polar metabolites would diffuse towards spaces not accessible to solvents, or establish chemical bonds with the organic components of the soils. Lastly, in our case, the fraction of non-extractable radioactivity did not increase much between 64 and 156 days of incubation. The non-extractable radioactivity observed at time 0 could be an artefact related to the technique of soxhlet extraction. It is probably due to bad exploration of the soil by the solvent (e.g. soil compression, preferential flow and wall effects). Nevertheless, our results showed that sequestration depends, at least to some extent, on the process of degradation and probably the subsequent diffusion of the metabolites formed (Fig. 5).

The ${ }^{14} \mathrm{C}$ mass balance for each sample revealed a deficit (loss) that fluctuated between $13.3 \pm 3.3 \%$ at time 0 (application of phenanthrene) and $36.4 \pm 3.4$ after 156 days of incubation (Fig. 5). These losses were probably partially caused by the handling of samples during analyses (extraction and concentration) and by direct volatilisation of phenanthrene from the soil; in particular, at time 0 during the evaporation of methanol. The deficit was thus $13 \%$. Cumulative losses could be described with a logarithmic function as a function of time (i.e., $7.011 \ln (\mathrm{t})+12.4)$, with a coefficient of determination $\left(R^{2}\right)$ of 0.72 . This shows that the losses decreased over time, certainly because of stronger soil-phenanthrene interactions and the formation of less volatile compounds.

\section{CONCLUSION}

We simultaneously monitored the principal processes of dissipation of ${ }^{14} \mathrm{C}$-phenanthrene and their interactions in an agricultural soil in controlled conditions over a period of 156 days. The results of this experiment and those obtained with a clay soil (data not shown) showed that when biological degradation occurs, there is an increase in sequestration and in leaching, as well as in the concentration in residues in pore water. The increase in availability for leaching is exclusively due to the formation of degradation products that are more soluble and/or less adsorbed than phenanthrene on the surface of the aggregates. In the same way, these compounds are responsible for the increase in the concentration in residues observed in the immobile water of the soil. The passage of phenanthrene degradation products into soil pore water occurs by diffusion due to the effect of a concentration gradient created by the degradation of phenanthrene (and the formation of degradation products) on the surface of the aggregates where it was initially 
adsorbed. In addition, this diffusion facilitates the sequestration of the compounds in the soil. Overall, our results suggest that in agricultural soils contaminated by strongly adsorbed organic compounds, diffusion, sequestration and leaching are driven by the process of biodegradation, and water pollution and sequestration are primarily controlled by metabolites.

\section{REFERENCES}

Amellal S., Boivin A., Perrin-Ganier C., Schiavon M. (2006) High sorption of phenanthrene in agricultural soils, Agron. Sustain. Dev. 26, 99-217.

Anderson J.P.E. (1994) Kinetics of pesticide biodegradation in soils: principles and applications, in: Copin A., Houins G., Pussemier L. Salembier J.F. (Eds.), Environmental Behaviour of Pesticides and Regulatory Aspects, European Study Service, Rixensart, Belgium, pp. 211-221.

Beulke S., Brown C.D., Fryer C.J., van Beinum W. (2004) Influence of kinetic sorption and diffusion on pesticide movement through aggregated soils, Chemosphere 57, 481-490.

Boivin A., Cherrier R., Schiavon M. (2005) Bentazon adsorption and desorption on agricultural soils, Agron. Sustain. Dev. 25, 309-315.

Breedveld G.D., Karlsen D.A. (2000) Estimating the availability of polycyclic aromatic hydrocarbons for bioremediation of creosote contaminated soils, Appl. Microbiol. Biotech. 54, 255-261.

Cerniglia C.E. (1993) Biodegradation of polycyclic aromatic hydrocarbons, Curr. Opin. Biotech. 4, 331-338.

Chang B.V., Shiung L.C., Yuan S.Y. (2002) Anaerobic degradation of polycyclic aromatic hydrocarbon in soil, Chemosphere 48, 717724

Cox L., Walker A. (1999) Studies of time-dependent sorption of linuron and isoproturon in soils, Chemosphere 38, 2707-2718.

Dictor M.C., Berne N., Mathieu O., Moussay A., Saada A. (2003) Influence of ageing of polluted soils on bioavailability of phenanthrene, Oil Gas Sci. Technol. 58, 481-488.

Duchaufour Ph. (1970) Précis de Pédologie, Masson et Cie.
Guennelon R. (1994) Le sol et l'eau, in: Bonneau M., Souchier B. (Eds.), Pédologie 2. Constituants et propriétés du sol, Masson, Paris, pp. 395-428.

Guimont S., Perrin-Ganier C., Réal B., Schiavon M. (2005) Effects of soil moisture and treatment volume on bentazon mobility in soil, Agron. Sustain. Dev. 25, 323-329.

Ho K.C., Hui K.C.C. (2001) Chemical contamination of the East River (Dongjiang) and its implication on sustainable development in the Pearl River Delta, Environ. Int. 26, 303-308.

Koskinen W.C., Rice P.J., Anhalt J.A., Sakaliene O., Moorman T.B., Arthur E.L. (2002) Sorption-desorption of "aged" sulfonylaminocarbonyltriazolidone herbicides in soil, J. Agric. Food Chem. 50, 5368-5372.

Lennartz B., Meyer-Windel S. (1995) The role of immobile water in unsaturated substrates, Hydrogeologie 4, 75-83.

Lichtfouse E., Schwarzbauer J., Robert D. (2005) (Eds.) Environmental Chemistry. Green chemistry and pollutants in ecosystems, Springer, Berlin, 69 chap., 780 p.

Renaud F.G., Brown C.D., Fryer C.J., Walker A. (2004) A lysimeter experiment to investigate temporal changes in the availability of pesticide residues for leaching, Environ. Pollut. 131, 81-91.

Scheunert I., Mansour M., Adrian Ph. (1991) Formation of conversion products and bound residues of chlorinated anilines in soil, Toxicol. Environ. Chem. 31/32, 107-112

Scow K.M., Johnson C.R. (1997) Effect of sorption on biodegradation of soil pollutants, Adv. Agron. 58, 1-56.

Soulas G. (1993) Evidence for the existence of different physiological groups in the microbial community responsible for 2,4-D mineralization in soil, Soil Biol. Biochem. 25, 443-449.

Walker A., Rodriguez-Cruz M.S., Mitchell M.J. (2005) Influence of ageing of residues on the availability of herbicides for leaching, Environ. Pollut. 133, 43-51.

Weigand H., Totsche K.U., Huwe B., Kogel-Knabner I., Richnow H.H (2002) Fate of anthracene in contaminated soil: transport and biochemical transformation under unsatured flow conditions, Eur. J. Soil Sci. 53, 71-81.

Yaduraju N.T. (1994) Influence of soil environmental factors on the efficacy of herbicides, Soil Environ. Pest. 265-292. 